\title{
Hemolytic Process
}

National Cancer Institute

\section{Source}

National Cancer Institute. Hemolytic Process. NCI Thesaurus. Code C40725.

Any cytolytic process occurring in erythrocytes, resulting in the release of hemoglobin. 